tected with large samples. Nevertheless, it is an indication and should be developed in any future survey.

By analyzing a wide range of teleost species (plus one reptile and two mammals), we have clearly demonstrated the universality of the five new intronic primer sets designed in this study. Rich profiles were observed when several PCR loci were amplified with one intronic system [i.e., several genes or pseudogenes $(3,7)]$. However, results could become unreadable when too many loci were not specifically amplified, leading to overloaded profiles (not usable data). Despite these exceptions, the markers are powerful for species identification by analysis of easily readable profiles; two or three of them have to be considered together to obtain a definitive diagnosis.

These primers are also promising for population genetics, as a rich polymorphism was observed that expressed several alleles discriminated by length polymorphism on agarose or acrylamide gels. They are already being used in as yet unpublished population genetic research $(11,12)$ on several fish species and are providing informative data.

We showed here the usefulness of these new EPIC-PCR genetic markers for fish identification at the species and population level by analyzing the length polymorphism of the doublestranded DNA. Depending on the fragment length obtained, a single-strand analysis (7) or SSCP (9) when the fragments are short, or a restriction fragment length polymorphism analysis when PCR fragments are monomorphic (5), could be more suitable alternatives for expressing the polymorphism.

\section{ACKNOWLEDGMENTS}

The authors would like to thank François Bonhomme (Laboratoire Génome des population, Interactions CNRS UMR 5000, SMEL 1, 32400 Sète) for useful discussions on the EPIC-PCR method, Lukas Ruber and Yabumoto Yoshikata for providing fish samples, and Robert Britton for his help in improving the English quality. A part of the study was performed with the help of European Union, Grant INCO, contract ICA4CT-2001-10024, called ECOCARP.

\section{REFERENCES}

1.Begg, G.A. and J.R. Waldman. 1999. A holistic approach to fish stock identification. Fish. Res. 43:35-44.

2.Aurelle, D., G. Cattaneo-Berrebi, and $\mathbf{P}$. Berrebi. 2002. Natural and artificial secondary contact in French western Pyrenees brown trout (Salmo trutta, L.) assessed by allozymes and microsatellites. Heredity 89:171-183.

3.Palumbi, S.R. and C.S. Baker. 1994. Contrasting population structure from nuclear and mtDNA of humpback wales. Mol. Biol. Evol. 11:426-435.

4.Bierne, N., S.A. Lenhert, E. Bédier, F. Bonhomme, and S.S. Moore. 2000. Screening for intron-length polymorphisms in peneaid shrimps using exon-primed introncrossed (EPIC)-PCR. Mol. Ecol. 9:233-235.

5.Chow, S. 1998. Universal primer for calmodulin gene intron in fish. Fish. Sci. 64:999-1000.

6.Chow, S. and K. Hazama. 1998. Universal primers for $\mathrm{S} 7$ ribosomal protein gene introns in fish. Mol. Ecol. 7:1255-1256.

7.Hassan, M., C. Lemaire, C. Fauvelot, and F. Bonhomme. 2002. 17 New Epic-PCR amplifiable introns in fish. Mol. Ecol. 2:334-340.

8.He, M. and D.S Haymer. 1997. Polymorphic intron sequences detected within and between populations of the Oriental fruit fly (Diptera: Tephritidae). Ann. Entomol. Soc. Am. 90: 825-831.
9.Sunnucks, P., A.C.C. Wilson, L.B. Beheregaray, K. Zenger, J. French, and A.C. Taylor. 2000. SSCP is not so difficult: the application and utility of single-stranded conformation polymorphism in evolutionary biology and molecular ecology. Mol. Ecol. 9:1699-1710.

10.Neto, E.D., C.J. Sanguinetti, and A.J.G. Simpson. 1995. Rapid silver staining and recovering of PCR products separated on polyacrylamide gels. BioTechniques 17:914-921.

11.Augros, S. 2002 Adaptations des populations de gobies du genre Pomatoschistus (Gill, 1863) aux écosystèmes lagunaires. Considérations écologiques et génétiques. Master's dissertation, University of Montpellier 2, Montpellier, France.

12.Ibanez, C. 2002. Structure génétique et écologie des populations de Cichla monoculus (Téléostéen Cichlidé) en Amazonie bolivienne. Master's dissertation, University of Montpellier 2, Montpellier, France.

Received 11 March 2003; accepted 20 June 2003.

Address correspondence to Touriya Atarhouch, Institut Agronomique et Vétérinaire Hassan II, Département de Parasitologie, Laboratoire de Biologie Moléculaire, BP 6202, 10101 Rabat, Morocco. e-mail: atarhouch_touriya@hotmail.com

\title{
Expression of active RNA-activated protein kinase (PKR) in bacteria
}

\author{
Graeme L. Conn \\ University of Manchester Institute of Science and Technology, Manchester, UK
}

BioTechniques 35:682-686(October 2003)

The expression of recombinant proteins in bacteria is a key tool for researchers interested in biochemical and biophysical analyses of protein functions in vitro. However, many key targets, especially eukaryotic proteins, do not express well for a variety of reasons (e.g., protein misfolding or the addition or lack of posttranslational modification). One such protein is the double-stranded RNA (dsRNA)activated protein kinase named PKR, which has been implicated in a variety of roles from the control of normal cell growth and differentiation to apoptosis (1). One of the most widely studied roles is the part PKR plays in the antiviral effects of interferon (IFN). Normally present in most mammalian cells at low levels, PKR expression is induced several-fold by IFN in response to viral infection (2) and, once activated, phosphorylates its target, the eukaryotic translation initiation factor 2 (eIF2) on serine 51 of the $\alpha$-subunit (3). This has the effect of increasing the affinity of the inactive guanosine diphosphate-bound form of eIF2 for 
the guanidine exchange factor (eIF2B), which leads to a reduced pool of active eIF2 molecules and a cessation of general translation $(4,5)$. Numerous viruses have evolved countermeasures to the effects of PKR using either short noncoding RNAs [e.g., adenovirus-associated RNA I (VA RNA $)(6,7)$ ] or viral proteins to inhibit its function.

The in vitro analysis of PKR function (activation and inhibition) and structure requires a source of active protein in a nonphosphorylated (i.e., nonactivated) form. While many studies have used the limited amounts of protein that can be purified from mammalian cell lines, one study has shown that a glutathione-S-transferase (GST)-PKR fusion protein can be expressed in Escherichia coli (8). Ideally, the protein should be highly purified but free of additional tags (e.g., GST). To this end, human PKR cDNA was cloned into a vector from the IMPACT ${ }^{\circledR}{ }_{-}$CN System (New
England Biolabs UK, Hitchin, UK) that uses an intein-chitin binding domain (CBD) fusion to give high protein purity and provides the target protein free of additional tags with the use of a single chromatographic step. PKR cDNA was PCR-amplified from plasmid pET-HisPKR using primers containing NdeI (forward) or XhoI (reverse) restriction sites and a 60:1 unit ratio of Taq and Pwo DNA polymerases (Roche Diagnostics, Lewes, UK). The amplified PCR product was ligated into a TA Cloning ${ }^{\circledR}$ Vector (Invitrogen, Paisley, UK) before being transferred to the expression vector pTYB2 via the $N d e I$ and $X h o I$ restriction sites (pTYB2/PKR). Lambda-protein phosphatase $(\lambda$-PP) cDNA was PCRamplified from $\lambda$ DNA using forward primer 5 '-CTGCAGTAAGAAGGAGATAAAGAGATGCGC-3' (PstI restriction site, italics; Shine-Dalgarno region, bold) and reverse primer 5'-GGTGCTAGCCTGCAGTCATGCGCCTTC-3' (PstI

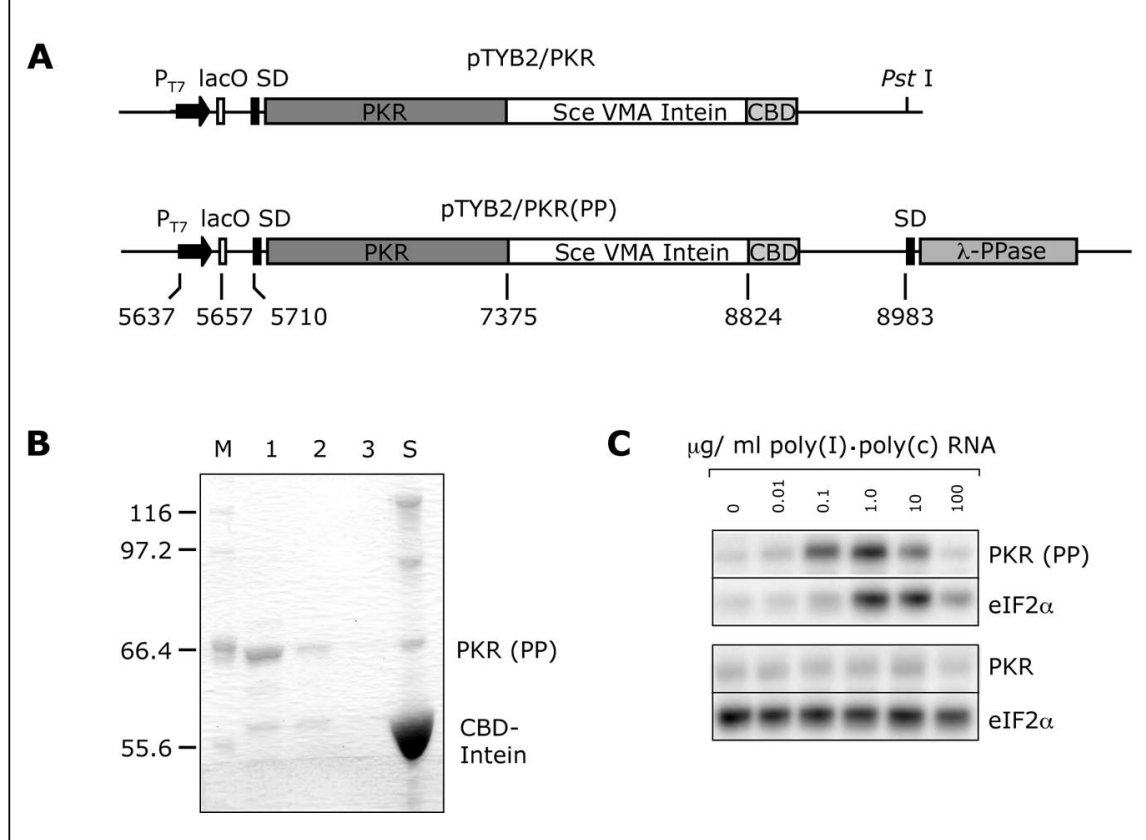

Figure 1. Cloning, expression, and purification of active RNA-activated protein kinase from bacterial cells. (A) The constructs based on the IMPACT-CN vector pTYB2 used for the expression of the RNA-activated protein kinase PKR. To obtain PKR from bacteria in a nonphosphorylated form, a second Shine-Dalgarno region (SD) followed by the $\lambda$-protein phosphatase $(\lambda$-PP) gene was inserted at a $P s t \mathrm{I}$ site following the intein/CBD coding region. (B) Sodium dodecyl sulfate-polyacrylamide gel electrophoresis (SDS-PAGE) analysis of PKR(PP) purification on chitin resin visualized by Coomassie staining. M, molecular weight marker (New England Biolabs); lanes 1-3, 1-mL fractions of PKR(PP) protein $(10 \mu \mathrm{L}$ loading); and $\mathrm{S}$, protein remaining bound to the chitin resin. $\mathrm{CBD}$, chitin binding domain. (C) Assays of PKR autophosphorylation with the poly(I) poly $(\mathrm{C})$ activator RNA in the presence of $[\gamma-$ ${ }^{32} \mathrm{P}$ ]ATP. PKR(PP) shows the expected RNA concentration-dependent activation profile [for both autophosphorylation and phosphorylation of the eukaryotic translation initiation factor $2 \alpha$ (eIF2 $\alpha$ )] peaking at approximately $1 \mu \mathrm{g} / \mathrm{mL}$ RNA (two upper panels). PKR expressed and purified under identical conditions but without $\lambda$-PP gives even levels of PKR autophosphoylation and eIF2 $\alpha$ phosphorylation at each RNA concentration (two lower panels). restriction site, italics). The PCR product was ligated into pTYB2/PKR (via a TA Cloning Vector) at a PstI site downstream of the Saccharomyces cerevisiae vacuolar membrane ATPase (Sce VMA) intein/ $\mathrm{CBD}$ coding region to create the expression vector pTYB2/PKR(PP) (Figure 1A). At each step, the correct insert orientations and sequences were confirmed by automated DNA sequencing.

A variety of $E$. coli strains for the expression of PKR and PKR(PP) (i.e., PKR with co-expression of $\lambda$-PP) were tested, including BL21(DE3) and its derivatives ER2566 (New England Biolabs; the strain supplied with the IMPACT-CN System), BL21 (DE3)CodonPlus ${ }^{\circledR}$-RIL and -RP cells (Stratagene Europe, Amsterdam, The Netherlands), pLysS, and pLysE. The level of protein expression was determined by sodium dodecyl sulfate-polyacrylamide gel electrophoresis (SDS-PAGE) with Coomassie ${ }^{\circledR}$ staining or immunoblotting with anti-PKR antibody (Santa Cruz Biotechnology, Santa Cruz, CA, USA). The significant expression of PKR and PKR(PP) proteins was observed only with the BL21(DE3)-CodonPlus-RIL strain (data not shown). Liquid cultures were grown at $37^{\circ} \mathrm{C}$ in LB medium to mid-log phase before the induction of protein expression by $0.3 \mathrm{mM}$ isopropyl- $\beta$-D-thiogalactoside (IPTG; Melford Laboratories Ltd., Ipswich, UK) and further growth at $30^{\circ} \mathrm{C}$ for $6 \mathrm{~h}$ or at $12^{\circ}-15^{\circ} \mathrm{C}$ for $18 \mathrm{~h}$. The buffer for cell lysis, protein binding to chitin resin, and washing of resin contained $20 \mathrm{mM}$ HEPES, pH 6.5, $1 \mathrm{M}$ $\mathrm{NaCl}, 1 \mathrm{mM}$ EDTA, $0.1 \%$ Triton ${ }^{\circledR} \mathrm{X}$ 100 , and $10 \%$ glycerol. To induce the intein self-cleavage reaction, the resin was quickly flushed with the same solution but at $\mathrm{pH} 8.5$, containing $50 \mathrm{mM}$ dithiothreitol (DTT), and incubated at $4^{\circ} \mathrm{C}$ for $12-18 \mathrm{~h}$. The typical yield from a 1-L bacterial culture and purification of PKR or PKR(PP) protein was $0.3-0.5 \mathrm{mg}$ (Figure 1B).

The activation of PKR by dsRNA is relatively well understood. The binding of dsRNA to the two N-terminal dsRNA binding domains of PKR causes a conformational change and activation by the autophosphorylation of PKR dimers $(9,10)$. Because of the requirement for dimerization on dsRNA, PKR activation shows a characteristic response 
to RNA concentration, increasing to a maximum from low RNA concentrations but falling again at higher concentrations. Following activation, PKR activity is no longer dependent on dsRNA. In vitro tests of PKR activation and function were conducted to assess the activity and phosphorylation state of the purified protein from the pTYB2/PKR and pTYB2/PKR(PP) vectors when they are expressed in BL21 (DE3)-CodonPlus-RIL cells. The PKR autophosphorylation and eIF $2 \alpha$ phosphorylation were assayed in $10-\mu \mathrm{L}$ reactions using poly(I)-poly $(\mathrm{C})$ (Amersham Biosciences, Little Chalfont, UK) as a dsRNA activator with approximately $0.2 \mu \mathrm{g}$ PKR or PKR(PP) and 0.5 $\mu \mathrm{g}$ eIF $2 \alpha$ in the presence of $\left[\gamma_{-}{ }^{32} \mathrm{P}\right]$ ATP in $50 \mathrm{mM}$ Tris buffer, $\mathrm{pH} \mathrm{7.8,} \mathrm{contain-}$ ing $50 \mathrm{mM} \mathrm{KCl}, 2 \mathrm{mM} \mathrm{MgCl} 2,2.5 \mathrm{mM}$ DTT, $10 \mu \mathrm{M}$ ATP, and $10 \%$ glycerol. The reaction mixtures were incubated at room temperature $\left(25^{\circ} \mathrm{C}\right)$ for $10 \mathrm{~min}$, and $5 \mu \mathrm{L} 3 \times$ SDS-polyacrylamide loading dye for $10 \mathrm{~min}$ were added to stop the reaction. The proteins were resolved on $10 \%$ SDS-polyacrylamide gels, dried, and exposed to a phosphorimager screen (Amersham Biosciences). Purified PKR(PP) showed the expected maximum in activation in response to a range of poly(I) $\operatorname{poly}(\mathrm{C})$ RNA concentrations and also phosphorylated its target protein eIF $2 \alpha$ (Figure 1C). Further tests of PKR activation [e.g., using a structured RNA fragment from the IFN$\gamma$ mRNA 5'-untranslated region (11)] showed similar RNA concentrationdependent activation of PKR, while assays including VA RNA show the expected inhibition of PKR at 20-50 $\mu \mathrm{g} / \mathrm{mL}$ (data not shown; Reference 12). PKR protein expressed and purified under identical conditions but without the co-expression of $\lambda$-PP did not show any dependence on RNA concentration for the activation or eIF $2 \alpha$ phosphorylation. The autophosphorylation of PKR is equal (and low; presumably many sites are already phosphorylated), and eIF2 $\alpha$ is heavily phosphorylated at all concentrations and in the absence of activator poly(I)·poly(C) RNA.

The co-expression of PKR and $\lambda$-PP is clearly applicable to both the GST (8) and intein/CBD fusion systems. The benefit of the latter is the builtin removal of the tag to yield highly purified target protein. Thus, the combination of the co-expression with the $\lambda$-PP, IMPACT-CN system, and BL21 (DE3) CodonPlus-RIL strain allows for the preparation of active PKR in an unphosphorylated form and in quantities required for material-intensive in vitro biochemical and biophysical studies. However, this method should also be generally applicable for use in other expression systems if required or for other proteins that may be expressed in a (partially) phosphorylated form in bacteria.

\section{ACKNOWLEDGMENTS}

The plasmid pET-HisPKR was the generous gift of Prof. M.B. Mathews of the University of Medicine and Dentistry of New Jersey (Newark, NJ, USA). This work was supported by a Wellcome Trust Career Development Fellowship (ref. no. 061444).

\section{REFERENCES}

1.Williams, B.R.G. 1997. Role of the doublestranded RNA-activated protein kinase (PKR) in cell regulation. Biochem. Soc. Trans. 25: 509-513.

2.Clemens, M.J. 1996. Protein kinases that phosphorylate eIF-2 and eIF2B, and their role in eukaryotic cell translational control, p. 139172. In J.W.B. Hershey, M.B. Mathews, and N. Sonenberg (Eds.), Translational Control. CSH Laboratory Press, Cold Spring Harbor, NY.

3.Colthurst, D.R., D.G. Campbell, and C.G. Proud. 1987. Structure and regulation of eukaryotic initiation-factor eIF-2-sequence of the site in the alpha-subunit phosphorylated by the heme-controlled repressor and by the double-stranded RNA-activated inhibitor. Eur. J. Biochem. 166:357-363.

4.Hershey, J.W.B. 1991. Translational control in mammalian cells. Annu. Rev. Biochem. 60:717-755

5.Samuel, C.E. 1993. The eIF-2-alpha proteinkinases, regulators of translation in Eukaryotes from yeasts to humans. J. Biol. Chem. 268:7603-7606.

6.Mathews, M.B. and T. Shenk. 1991. Adenovirus virus-associated RNA and translation control. J. Virol. 65:5657-5662.

7.Kitajewski, J., R.J. Schneider, B. Safer, S.M. Munemitsu, C.E. Samuel, B. Thimmappaya, and T. Shenk. 1986. Adenovirus VAI RNA antagonizes the antiviral action of interferon by preventing activation of the interferon-induced eIF-2-alpha kinase. Cell 45:195-200.

8.Matsui, T., K. Tanihara, and T. Date. 2001. Expression of unphosphorylated form of human double-stranded RNA-activated protein kinase in Escherichia coli. Biochem. Biophys.
Res. Commun. 284:798-807.

9.Robertson, H.D. and M.B. Mathews. 1996 The regulation of the protein kinase PKR by RNA. Biochimie 78:909-914.

10.Ung, T.L., C. Cao, J.M. Lu, K. Ozato, and T.E. Dever. 2001. Heterologous dimerization domains functionally substitute for the double-stranded RNA binding domains of the kinase PKR. EMBO J. 20:3728-3737.

11.Ben-Asouli, Y., Y. Banai, Y. Pel-Or, A. Shir, and R. Kaempfer. 2002. Human interferongamma mRNA autoregulates its translation through a pseudoknot that activates the interferon-inducible protein kinase PKR. Cell 108:221-232.

12.Mellits, K.H., T. Pe'ery, and M.B. Mathews. 1992. Role of the apical stem in maintaining the structure and function of adenovirus virusassociated RNA. J. Virol. 66:2369-2377.

Received 4 April 2003; accepted 23 June 2003.

Address correspondence to Graeme L. Conn, Department of Biomolecular Sciences, UMIST, P.O. Box 88, Manchester, M60 1QD, UK. e-mail: graeme.l.conn@ umist.ac.uk 